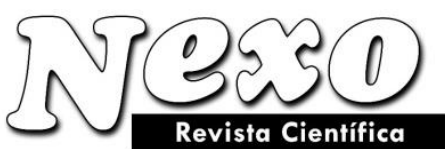

Vol. 33, No. 02, pp. 468-475/Diciembre 2020

\title{
An investigation of the undesirable outputs congestion in data envelopment analysis
}

\section{Una investigación de la congestión de productos no deseados en el análisis de envolvente de datos}

\author{
Soodabeh Nazari ${ }^{1}$, Mohsen Rostamy-Malkhalifeh ${ }^{2 *}$, Ali Hamzehee ${ }^{1}$ \\ ${ }^{1}$ Department of Mathematics, Kerman Branch, Islamic Azad University, Kerman, Iran \\ ${ }^{2}$ Department of Mathematics, Science and Research Branch, Islamic Azad University, \\ Tehran, Iran
}

Corresponding author Email: Mohsen_rostamy@yahoo.com

(recibido/received: 03-July-2020; aceptado/accepted: 03-September-2020)

\begin{abstract}
Congestion is one of the most important subjects in Data Envelopment Analysis (DEA) which helps the Decision Maker (DM) to decide about changing the size of units. The estimation of congestion has attractive advantages from different perspectives. For example, the total cost of a partiular DMU, in which the congestion occurs, can be reduced by the decreases in inputs. On the other hand, the output of units can be increased by the recognizing and eliminating the congestion of DMUs and so, the total profit of decision making units can be increased. Hence, the management is eager to know how to recognize and eliminate the congestion of units. Most of the existing methods to estimation of the congestion in the literature consider only the desirable outputs. This study focuses on the evaluation of congestion in the presence of undesirable outputs and proposes an approach to recognize the congestion of units. The method is demonstrated on a numerical example to illustrate the validity of the proposed method.

Keyword: Data Envelopment Analysis; Congestion; Undesirable outputs; Decision making units.
\end{abstract}

\section{RESUMEN}

La congestión es uno de los temas más importantes en el análisis envolvente de datos (DEA) que ayuda al responsable de la toma de decisiones (DM) a decidir sobre el cambio de tamaño de las unidades. La estimación de la congestión tiene atractivas ventajas desde diferentes perspectivas. Por ejemplo, el costo total de una DMU en particular, en la que ocurre la congestión, puede reducirse mediante la disminución de los insumos. Por otro lado, la producción de unidades se puede incrementar reconociendo y eliminando la congestión de las DMU y así, se puede incrementar el beneficio total de las unidades de toma de decisiones. Por lo tanto, la gerencia está ansiosa por saber cómo reconocer y eliminar la congestión de unidades. La mayoría de los métodos existentes para estimar la congestión en la literatura consideran solo los resultados deseables. Este estudio se centra en la evaluación de la congestión en presencia de salidas 
indeseables y propone un enfoque para reconocer la congestión de unidades. El método se demuestra en un ejemplo numérico para ilustrar la validez del método propuesto.

Palabra clave: Análisis envolvente de datos; Congestión; Salidas indeseables; Unidades de toma de decisiones.

\section{INTRODUCCION}

Data Envelopment Analysis (DEA) is a non-parametric methodology for assessing the relative efficiency of Decision Making Units (DMUs) with multiple inputs and multiple outputs (Charnes et al. [1], Banker et al. [2].The estimation of congestion is an attractive issue in DEA. If the increases (decreases) in inputs leads to the decreases (increases) in outputs, then congestion occurs. Many scholars have been attracted to the evaluation of the congestion. Färe and Grosskopf [3] introduced the economic concept of congestion. Färe et al. [4] suggested a radial model to recognize the congestion. Cooper et al. [5] proposed a slackbased method (CTT model) to evaluate the congestion of units which distinguished the congested inputs and also, obtained the amount of congestion of inputs as the difference between the observed value and the expected value. Brocket et al. [6] developed CTT model to identify the congestion of units in Chinese industry.

Cooper et al. [7] proposed an additive model to evaluate the congestion of DMUs. Cooper et al. [8] presented a single- model method to estimate the congestion. Jahanshahloo and Khodabakhshi [9] proposed a method based on the combination of inputs. Khodabakhshi [10] developed an approach to identify the congestion of units in the presence of stochastic data. Wei and Yan [11] used the outputoriented additive model to propose the necessary and sufficient conditions about the existence of congestion. Tone and Sahoo [12] presented a slack-based method to evaluate the scale elasticity in the presence of congestion. They introduced two basic concepts, namely, weak congestion and strong congestion and demonstrated that the congestion could be recognized by the status with having negative production elasticity. Sueyoshi and Sekitani [13] proposed a modified method to measure the congestion of units in the presence of the existing of the alternative optimal solutions.

On the other hand, the traditional DEA considers each DMU as a black box. This means that, each unit has a single process, however, there are also many applications that consider each DMU as a network of processes (for more studies about Network DEA models, see Kao [14], Tone and Tsutsui [15], Lozano [16], Lozano and Khezri [17]). Wang [18] considered the two-stage process in banking industry to estiamte the congestion of units. For more studies about congestion, see Asgharian et al. [19], Flegg and Allen [20]. Odeck [21] considered the impact of the congestion of inputs, such as fuel consumption and the total number of workers on the efficiency in the Norwegian bus industry.

Quan and Yan [22] pointed out that the heavy industry emits many perilous pollutants such as sulfur dioxide, nitrogen oxides, carbon monoxide and hydrocarbons which are as the undesirable outputs of production process. The final costs of reducing the emitions of pollutants such as sulfur dioxide, nitrogen oxides, carbon monoxide and hydrocarbons may be changed according to the different environmental activities. The current environmental regulations do not provide any conditions for achieving to the minimum total cost. Murty et al. [23] Showed that there exists a significant relationship between the environmental efficiency and the protection of the climate resources.

It should be noted that, most of the existing methods for the estimation of congestion in the literature consider the situation that the production process only produces the desirable outputs and do not consider the situation that the undesirable outputs can be produced (see Cooper et al. [24]), Brocket et al. [25], Khoveyni et al. [26], Wei et al. [27] and Hosseinzadeh Lotfi et al. [28] for more details). Wu et al.[29] applied the method of Seiford and Zhu [30] to address the undesirable outputs and then formulated an approach Combined with the study of Wei and Yan [27] to measure the congestion of units in the presence of the desirable and undesirable outputs. Given that, the reduction in the undesirable outputs can result in the increases in the desirable outputs, therfore, it is important to include the undesirable outputs in the evaluation of decision making units. This study focuses on the situation that the production process generates the undesirable outputs and proposes a method to identify the congestion of units. 
The rest of this paper is organized as follows: Section 2 provides the preliminaries and reviews the singlemodel method of Khodabakhshi [10]. Section 3 proposes a method to recognize the congestion of units in the presence of undesirable outputs. Numerical example is provided in section 4 . Section 5 concludes the paper.

\section{PRELIMINARIES}

One of the most attractive issues in DEA is the estiamtion of congestion of DMUs. The concept of congestion is widely used in various sciences such as medicine, traffic eggineering, transportation and population. In economics, congestion occurs when the increases in inputs lead to the decreases in outputs, without improving other inputs or outputs. In reverse, congestion occurs when the decreases in inputs lead to the increases in outputs, without worsening other inputs or outputs. The congestion estimation and the suggestion of methods to eliminate the congestion of units have attractive advantages from different perspectives.

1. The total cost of a partiular DMU, in which the congestion occurs, can be reduced by the decreases in congested inputs.

2. The output of units can be increased by the recognizing and eliminating the congestion of DMUs and so, the total profit of decision making units can be increased.

Therefore, the congestion assessment has many economic benefits and so, the DM is eager to know how to recognize and eliminate the congestion of units. In the following, we review the single-model method of Khodabakhshi [10].

\subsection{The single-model method of Khodabakhshi [10]}

Khodabakhshi [10] proposed a single-model method based on the input relaxation model (jahanshahloo and Khodabakhshi [31]) to identify the input congestion of units as follows:

$$
\begin{aligned}
& \text { Maximize } \quad \phi_{0}+\varepsilon\left(\sum_{i=1}^{m} s_{i 1}^{-}+\sum_{r=1}^{s} s_{r}^{+}-\sum_{i=1}^{m} s_{i 2}^{+}\right) \\
& \text {S.to } \quad \sum_{j=1}^{n} \lambda_{j} x_{i j}+s_{i 1}^{-}-s_{i 2}^{+}=x_{i 0}, \quad i=1, \ldots, m \\
& \sum_{j=1}^{n} \lambda_{j} y_{r j}-\phi_{0} y_{r j}-\phi_{0} y_{r 0}-s_{r}^{+}=0, \quad r=1, \ldots, s \\
& \sum_{j=1}^{n} \lambda_{j}=1 \\
& s_{i 1}^{-}, s_{i 2}^{+}, \lambda_{j}, s_{r}^{+} \geq 0, \quad i=1, \ldots, m ; j=1, \ldots, n ; r=1, \ldots, s .
\end{aligned}
$$

The method of Khodabakhshi [10] reduces the number of required models for recognizing the congestion, which is certainly important from the perspective of computational time.

It should be noted that, the traditional DEA models only consider the situation that the production process generates the desirable outputs. However, in many real world applications, the undesirable outputs, such as $\mathrm{CO} 2$ emissions and any production waste, can be produced during the production process of the industrial activities. Therefore, an imporatnt issue in DEA is how to include the undesirable outputs in the production process. For more studies about the undesirable outputs in DEA, see Fare et al. [32], Seiford and Zhu [33], Yang et al. [34]. Yang and Pollitt [35], Halkos and Petrou [36]). 
The next section proposes a new method to identify the congestion of units in the presence of undesirable outputs.

\section{THE PROPOSED METHOD TO RECOGNIZE THE COGESTION}

In this section, we consider the situation that the production process produces the undesirable outputs and propose a model to recognize the congestion of units.

The conventional DEA models for estimation of congestion only considers the inputs congestion. Given that, the reduction in the undesirable outputs can result in the increases in the desirable outputs, therfore, it is important to include the undesirable outputs in the evaluation of decision making units. In this paper, we suggest a new model to estimate the inputs congestion and the undesirable outputs congestion. For this purpose, we formulate model (2) as follows:

$$
\begin{array}{lcc}
\text { Maximize } & \phi_{0}+\varepsilon\left(\sum_{i=1}^{m}-s_{i}^{-c}+\sum_{r=1}^{s} s_{r}^{+}-\sum_{i=1}^{m} s_{i 2}^{+}+\sum_{t=1}^{k}-s_{t}^{-b c}-\sum_{t=1}^{k} s_{t b}^{+}\right) \\
\text {S.t } & \sum_{j=1}^{n} \lambda_{j} x_{i j}+s_{i}^{-c}-s_{i 2}^{+}=X_{i 0} & i=1, \ldots, m \\
& \sum_{j=1}^{n} \lambda_{j} y_{r j}-\phi_{0} y_{r 0}-s_{r}^{+}=0 & \\
\sum_{j=1}^{n} \lambda_{j} b_{t j}+s_{t}^{-b c}-s_{t b}^{+}=b_{t 0} & \\
\sum_{j=1}^{n} \lambda_{j}=1 & \\
& s_{i}^{-c}, s_{i 2}^{+}, \lambda_{j}, s_{r}^{+}, s_{t b}^{+}, s_{t}^{-b c} \geq 0
\end{array}
$$

Where, $s_{i}^{-c}$ and $s_{t}^{-b c}$ show the amount of congestion in the $i^{t h}$ input and the $t^{t h}$ undesirable output, respectively. Model (2) maximizes the desirable outputs and minimizes the inputs and the undesirable outputs. This model not only distinguishes the congested inputs and the undesirable outputs, but also measures the amount of congestion of each input and undesirable output.

The proposed method has the main properties:

1. Detecting the inputs congestion.

2. Recognizing the undesirable outputs congestion.

3. Proposing a model to identify the congestion of universities.

4. Investigating the impact of congestion on the inefficiency of units and determining the factors that lead to the congestion.

5. Investigating the reasons for the decreases in outputs due to the increases in inputs.

\section{NUMERICAL EXAMPLE}

In this section, the results of applying the proposed model to assess the performance and the congestion of 21 colleges of Zahedan branch of the Islamic Azad University in Iran, are reported. Each college is considered as a DMU with three inputs (the number of enrolled students $\left(x_{1}\right)$, the number of faculty members $\left(x_{2}\right)$, the number of courses provided by visiting lecturer $\left(x_{3}\right)$ ) and three desirable outputs (the number of graduates $\left(y_{1}\right)$, the number of students admitted to higher level $\left(y_{2}\right)$ and the number of research projects $\left(y_{3}\right)$ ) and one undesirable output (the number of expelled students $\left(y_{4}\right)$ ). Table 1 reports the data of units. The data has been collected based on the documents available in the faculties. It should 
be noted that, the amount of $y_{3}$ that includes the number of research papers, e.g. ISI papers, ISC papers and etc, and also other research works can be considered as the research score for the faculty members according to the faculty members promotion regulations.

Table 1. The data of colleges.

\begin{tabular}{|c|c|c|c|c|c|c|c|}
\hline DMU & $x_{1}$ & $x_{2}$ & $x_{3}$ & $y_{1}$ & $y_{2}$ & $y_{3}$ & $y_{4}$ \\
\hline 1 & 433 & 5 & 88 & 56 & 1 & 45 & 15 \\
\hline 2 & 242 & 1 & 55 & 35 & 2 & 10 & 8 \\
\hline 3 & 233 & 2 & 38 & 46 & 6 & 40 & 7 \\
\hline 4 & 406 & 1 & 65 & 51 & 6 & 0 & 12 \\
\hline 5 & 989 & 10 & 140 & 75 & 2 & 60 & 18 \\
\hline 6 & 1276 & 9 & 145 & 148 & 2 & 60 & 22 \\
\hline 7 & 2190 & 6 & 165 & 189 & 2 & 20 & 25 \\
\hline 8 & 634 & 6 & 82 & 68 & 4 & 40 & 18 \\
\hline 9 & 757 & 4 & 78 & 103 & 2 & 10 & 12 \\
\hline 10 & 650 & 12 & 64 & 25 & 2 & 130 & 20 \\
\hline 11 & 525 & 6 & 90 & 43 & 8 & 120 & 21 \\
\hline 12 & 1020 & 2 & 100 & 116 & 1 & 0 & 24 \\
\hline 13 & 1718 & 11 & 140 & 111 & 4 & 50 & 24 \\
\hline 14 & 1025 & 6 & 120 & 80 & 3 & 90 & 17 \\
\hline 15 & 655 & 11 & 88 & 30 & 10 & 50 & 16 \\
\hline 16 & 924 & 5 & 92 & 39 & 1 & 20 & 21 \\
\hline 17 & 360 & 6 & 72 & 31 & 1 & 20 & 10 \\
\hline 18 & 779 & 8 & 102 & 146 & 1 & 10 & 14 \\
\hline 19 & 589 & 5 & 92 & 115 & 1 & 0 & 15 \\
\hline 20 & 441 & 4 & 80 & 35 & 1 & 20 & 13 \\
\hline 21 & 258 & 5 & 50 & 11 & 1 & 20 & 12 \\
\hline & & & & & & & \\
\hline
\end{tabular}

Now, we use the proposed method to recognize the congested inputs and the congested undesirable outputs. The results are reported in Table 2.

Table 2. The results of model (2).

\begin{tabular}{|c|c|c|c|c|c|}
\hline DMU & $1 / \phi^{*}$ & $s_{1}^{-c}$ & $s_{2}^{-c}$ & $s_{3}^{-c}$ & $s_{t}^{-b c}$ \\
\hline 1 & 0.5327 & 0 & 0 & 0 & 6.5918 \\
\hline 2 & 0.3269 & 0 & 0 & 0 & 12.3645 \\
\hline 3 & 0.7354 & 0 & 0 & 0 & 11.467 \\
\hline 4 & 0.7446 & 0 & 0 & 0 & 6.1804 \\
\hline 5 & 0.7114 & 17.5722 & 2.2166 & 17.3055 & 3.5944 \\
\hline 6 & 1 & 0 & 0 & 0 & 0 \\
\hline 7 & 1 & 0 & 0 & 0 & 0 \\
\hline 8 & 0.670 & 0 & 0 & 0 & 3.4132 \\
\hline 9 & 0.6245 & 0 & 0 & 0 & 11.6444 \\
\hline 10 & 1 & 0 & 0 & 0 & 0 \\
\hline
\end{tabular}




\begin{tabular}{|c|c|c|c|c|c|}
\hline 11 & 1 & 0 & 0 & 0 & 0 \\
\hline 12 & 0.6153 & 0 & 0 & 0 & 1 \\
\hline 13 & 0.8694 & 211.3081 & 4.7173 & 6.2237 & 1.4312 \\
\hline 14 & 0.9389 & 198.0189 & 0 & 7.8842 & 4.4021 \\
\hline 15 & 1 & 0 & 0 & 0 & 0 \\
\hline 16 & 0.2980 & 0 & 0 & 0 & 1.2571 \\
\hline 17 & 0.2623 & 0 & 0 & 0 & 11.8383 \\
\hline 18 & 0.7733 & 0 & 2 & 0 & 11 \\
\hline 19 & 0.6090 & 0 & 0 & 0 & 10 \\
\hline 20 & 0.2801 & 0 & 0 & 0 & 9.061 \\
\hline 21 & 0.1818 & 0 & 0 & 0 & 9.1666 \\
\hline
\end{tabular}

The second column of Table 2 shows the efficiency of units. As we see, 5 colleges are efficienct and 16 colleges are inefficient units. The last four columns of Table 2 show the amount of inputs congestion and the undesirable outputs congestion, respectively. The inefficient units have the congestion in some inputs and all of them have the congestion in the undesirable output. Therfore, the congested inputs and the congested undesirable output lead to the inefficiency of DMUs. It should be noted that, the increases in the number of expelled students $\left(y_{4}\right)$ can reduce other outputs, such as the number of graduates and the number of students admitted at higher levels. Therefore, the undesirable output has the largest intensity for creating the inefficiency of units. The obtained results can help the DM to decide about increasing or decreasing the size of a particular DMU.

\section{CONCLUSION}

This study considered the production process in the presence of the undesirable outputs and proposed a method to recognize the inputs congestion and the undesirable outputs congestion. In this paper, we showed that, if we only increase the number of enrolled students and keep the other inputs, such as the faculty members, unchanged, then, the outputs, such as the number of research projects will be reduced, because of the faculty members have the limited time. In other words, the increases in the number of postgraduate students will increase the number of research projects, while the increases in the number of students at the bachelor's degree level may reduce the number of research projects. Because of the faculty members can not be able to spend enough time for students as in the past. Also, the increases in the number of expelled students can reduce other outputs, such as the number of graduates and the number of students admitted at higher levels. Therefore, the congested undesirable outputs lead to the decreases in desirable outputs and the efficiency of units.

\section{REFERENCES}

Charnes, A., Cooper, W.W., Rhodes, E. (1978). Measuring the efficiency of decision making units, European Journal of Operational Research, 2, 429-444.

Banker, R.D., Charnes, A., Cooper, W.W. (1984). Some models for estimating technical and scale inefficiencies in DEA, Management Science, 30, 1078-1092.

Fare, R. and Grosskopf, S., (1983). Measuring congestion in production. Zeitschrift fur Nationalokonomie, 43 (3), 257-271.

Fare, R. and Grosskopf, S. and Lovell, C. A. K. (1985). The Measurement of Efficiency of Production, KluwerNijhoff Publishing, Boston, Mass, USA.

Cooper, W. W., Thompson, R. G.. Thrall, R. M. (1996). Introduction: extensions and new developments in DEA, Annals of Operations Research, 66, 3-45.

Brockett, P.L., Cooper, W.W., Wang, Y., and Shin, H. (1998). Inefficiency and congestion in Chinese production before and after the 1978 economic reforms, Socio-Economic Planning Sciences, 32 (1), 1-20. 
Cooper, W. W., Seiford, L. M., and Zhu, J. (2000). A unified additive model approach for evaluating inefficiency and congestion with associated measures in DEA, Socio-Economic Planning Sciences, 34 (1), 1-25.

Cooper, W. W., Deng, H., Huan, Z. M., Li, S. L. (2002). A one-model approach to congestion in data envelopment analysis, European Journal of Operational Research ,vol. 36,pp. 231-238, ng Sciences, 34, 1-25.

Jahanshahloo, G. R., Khodabakhshi, M. (2004). Suitable combination of inputs for improving outputs in DEA with determining input congestion: considering textile industry of China, Applied Mathematics and Computation, 151(1), 263-273.

Khodabakhshi, M. (2009). A one-model approach based on relaxed combinations of inputs for evaluating input congestion in DEA", Journal of Computational and Applied Mathematics, 230 (2), 443-450.

Wei, Q. L., Yan, H. (2004). Congestion and returns to scale in data envelopment analysis. European Journal of Operational Research, 153, 641-660.

Tone, K. and Sahoo, B. K. (2004). Degree of scale economies and congestion: a unified DEA approach, European Journal of Operational Research, 158 (3), 755-772.

Sueyoshi, T., Sekitani, K. (2009). DEA congestion and returns to scale under an occurrence of multiple optimal projections, European Journal of Operational Research, 194, 592-607.

Kao C. (2018). A classification of slacks-based efficiency measures in network data en- velopment analysis with an analysis of the properties possessed. Eur J Oper Res; 270, 1109-21.

Tone K, Tsutsui M. (2009). Network DEA: a slacks-based measure approach. Eur J Oper Res; 197, 243-52.

Lozano S. (2015). Alternative SBM model for network DEA. Comput Ind Eng ; 32, 33-40.

Lozano, S., \& Khezri, S. (2019). Network DEA smallest improvement approach. Omega, 102140.

Wang, K., Huang, W., Wu, J., \& Liu, Y. N. (2014). Efficiency measures of the Chinese commercial banking system using an additive two-stage DEA. Omega, 44, 5-20.

M. Asgharian, M. Khodabakhshi, and L. Neralic. (2010). Congestion in stochastic data envelopment analysis: an input relaxation approach, International Journal of Statistics and System Science, 5, 84-106.

Flegg, A. T. and Allen, D. O. (2009). Congestion in the Chinese automobile and textile industries revisited, SocioEconomic Planning Sciences, 43 (3), 177-191.

Odeck J. (2006). Congestion, ownership, region of operation, and scale: their impact on bus operator performance in Norway. Socio- Economic Planning Sciences, 40, 52-69.

Kwon, O.S., W.C. Yun and D. Hwan. (2005). Market value for thermal energy of cogeneration: using shadow price estimation applied to cogeneration systems in Korea, Energy Policy, 33, 1789-1792.

Murty, M.N., S. Kumar and P. Mahua. (2006). Environmental regulation productive efficiency and cost of pollution abatement: a case study of sugar industry in India, Journal of Environmental Management, 79, 1-9.

Cooper, W.W., Gu, B., Li, S. (2001). Comparisons and evaluations of alternative approaches to the treatment of congestion in DEA," European Journal of Operational Research, 132 (1), 62- 74.

Brockett, P. L., Cooper, W. W., Shin, H.C., Wang, Y. (1978). Inefficiency and congestion in Chinese production before and after the economic reforms," Socio-Economic Planning Sciences, 32 (1), 1-20.

Khoveyni, M., Eslami, R., Khodabakhshi, M., Jahanshahloo, G.R. and Hosseinzadeh Lotfi, F. (2013). Recognizing strong and weak congestion slack based in data envelopment analysis," Computers and Industrial Engineering, 64, 731-738.

Wei, Q. L. and Yan, H. (2004). Congestion and returns to scale in data envelopment analysis," European Journal of Operational Research, 153 (3), 641-660.

[Hosseinzadeh Lotfi, F. , Jahanshahloo, G. R., Khodabakhshi, M., Rostamy-Malkhlifeh, ., Moghaddas, Z., and Vaez-Ghasemi, M. (2013). A review of ranking models in data envelopment analysis,” Journal of Applied Mathematics, ArticleID492421, 20 .

Wu, J., An, Q., Xiong, B. and Chen, Y. (2013). Congestion measurement for regional industries in China: a data envelopment analysis approach with undesirable outputs," Energy Policy, 57, 7-13.

Seiford, L.M. and Zhu, J. (2002). Model ing undesirable factors inefficiency evaluation," European Journal of Operational Research, 142, (1),16-20.

Jahanshahloo, G. R., and Khodabakhshi, M. (2004). Suitable combination of inputs for improving outputs in DEA with determining input congestion: Considering textile industry of China. Applied mathematics and computation, 151 (1), 263-273.

Fare, R., Grosskopf, S., Lovell, C. A. K. and Yaisawarng, S. (1993). Derivation of Shadow Prices for Undesirable Outputs: A Distance Function Approach. The Review of Economics and Statistics, 75 (2), 374-380.

Seiford, L.M. and Zhu, J. (2001). Modeling undesirable factors in efficiency evaluation. European Journal of Operational Research, 142, 16-20. 
Yang, C.C., Hsiao, C. K. and Yu, M.M. (2008). Technical efficiency and impact of environmental regulations in farrow to finish swine production in Taiwan. Agricultural Economics, 39 (1), 51-61.

Yang, H. and Pollitt, M. (2010).The necessity of distinguishing weak and strong disposability among undesirable outputs in DEA: Environmental performance of Chinese coal-fired power plants. Energy Policy, 38, 44404444.

Halkos, G., \& Petrou, K. N. (2019). Treating undesirable outputs in DEA: A critical review. Economic Analysis and Policy, 62, 97-104. 